\title{
The Use of Serious Games in Preschool Education
}

\author{
https://doi.org/10.3991/ijet.v12.i11.6991 \\ Georgia Kokkalia $\left.{ }^{\bowtie}\right)$, Athanasios Drigas \\ NCSR DEMOKRITOS, Athens, Greece \\ gioulina@hotmail.com \\ Alexandra Economou, Petros Roussos \\ University of Athens, Athens, Greece \\ Spyridoula Choli \\ NCSR DEMOKRITOS, Athens, Greece
}

\begin{abstract}
A brief review is presented in order to underlie the importance of serious games in preschool education. Their role is examined according to the educational perspectives that are explored in preschool settings including also their role in special preschool education. The domains of literacy, maths, cognitive \& motor skills, creativity, communication and special education are investigated. Also, the beliefs of teachers about using games for teaching and learning are interviewed.
\end{abstract}

Keywords—games, preschool education, special preschool education

\section{$1 \quad$ Introduction}

Today's kindergarten children have been called, among other names, the net generation. As they enroll through the education system, they are often exposed to materials and manipulative and recently, a movement has started for using games in teaching and training. The idea of games as mean of offering knowledge has been around for some time and are usually referred as serious games. This initiative, known as serious games, has changed the way that educators viewed instruction to meet the needs of the children and serious games have impacted the military and firefighters, the medical and higher business education as well as the mainstream and special education [1]. As a result, the home school and virtual school market is growing around the world while parents and teachers look for strategies to help children to learn.

On the other hand, serious games have been under heavy criticism from different cases [2]. Trying to answer the question of what a game is we are in front of many different definitions, some wider and some more narrow which are make us feel confused [3]. As a result, defining of what a game is can be really hard and so Parlett [4] stated that the word game is used frequently and for many different activities that there is no need of any proposed definition. However, two important aspects of games; education and entertainment, are reflected in the term serious games, which in 
itself is an oxymoron as one could argue that education is not entertaining, but is serious.

Additionally, it seems clear that the possibilities for using games in learning situations are vast and many studies show the pedagogical potential of serious games in edutainment and e-learning[5]. Using games in education is not a new thing and especially in early education, teachers often implement games in order to make the lesson more playful, creative and appealing to children. Recently, serious games are gaining popularity not only as games, but as promising educational tools too. Advocates support, that serious games can combine learning and play and can be integrated into the teaching procedures [5].

Evidence from the research also, suggests that games can be used effectively in the school classroom, both within the subject curriculum with its emphasis on information and knowledge and within more skills and competence programs. As researchers state, if we would like to make school more engaging and more relevant to real life and if we want to give children skills more appropriate to our century, then more careful analysis needs to be conducted on the serious games [6].

Taking the above under consideration we will try to give a brief overview of the most representative studies of the last decade (2006-2016), which concentrate on the use of games in preschool education according to the educational perspective. The areas of literature, maths, entairtenment, cooperation and the field of cognitive skills that are exanimated in kindergarten are investigated as well as the area of special education and the support of games. Lastly, the beliefs and the views of teachers about the use of games in kindergarten are presented briefly.

\section{Games and Literature}

Computer games have been criticized since long time as some researchers say that they encourage violent behavior in children while others state that they make children hyperactive, unsociable and are bad for their eyes. Others support the view that children may show lack of interest in literature and in reading developing students with no interests. On the other hand, many people are troubled with the themes that constitute certain games, and concerned with the intensity of involvement and amount of time that children spend on them. However, some games can be quite instructive and enlightening as some games are in complex environments, and very little is known about their instructional effectiveness[7]. Later, we present some studies that show that serious games may help preschoolers to enhance better literature skills with their support.

More specifically, Segers and Verhoeven [8] studied about training by computer in kindergarten where intensive vocabulary training by computer was undertaken in a kindergarten program in the Netherlands. In the intervention, 67 children played vocabulary games on the computer while a control group of 97 kindergartners followed the regular curriculum. The results of the study showed positive effects of the computer training on the curriculum-dependent vocabulary test besides a trend was found 
towards positive effects of the computer training on a curriculum-independent test for children in their second year of kindergarten.

Furthermore, some researchers believe that serious games are both entertaining and instructive. Taking this into account, a recent study presents the learning effects of the serious game Mijn naam is Haas (My name is Haas) upon vocabulary growth in children (age $4-7$ ). The results showed that there was vocabulary growth and a significant interaction between the game and the vocabulary with a positive result in the experimental group [9].

In the light of the above studies, an interesting survey introduced Melody Touch as an interactive game for learning English from songs. This game combines the education and entertainment applications with the goal to help children improve their language skills by learning songs. Melody Touch is developed on a tablet running Android operating system and consists of three main parts (purchasing system, game module, review mistake session). During playing, the user has to select one of given words to fill in a blank displayed as part of song lyric shown while listening to music. Words that have the same sound or the same meaning have to be chosen and thus, the game may help children to improve their listening skills and their vocabulary [10].

\section{Using games to teach a second language}

Many studies have been conducted to investigate the role of computer games and their value in learning second language. The research of computer game based language learning focuses on computer games as a virtual environment that supports language learning on its own and computer games as a tool to facilitate collaborative learning [11]. Some researchers claim that online computer games may show potential not just for engaging and entertaining users, but also in promoting learning.

Specifically, in Turkey children spend time playing computer games, which are mostly in English. According to a study based on phenomenological theoretical framework the researchers investigated Turkish young learners' experiences of language learning while playing computer games. The findings of this study showed that in relation to English learning and technology, online games promotes language learning and especially vocabulary skills while the researchers advise children to play online games that are useful resources for language learning [12].

Moreover, in another study, the results of using a digital computer game and its role on promoting Iranian children's vocabulary learning were explored. In the experimental group, the SHAIEx digital game was used whereas in the control group, English vocabulary was taught through traditional methods. At the end of the teaching period, the participants' performances were compared. The results indicated that the final score of the children in the experimental group was significantly higher than those in the control group, indicating the positive effect of using digital games in teaching English vocabulary to children. It can be concluded from the results of this study that serious games have positive effects on the learning process as using such games there are better results in motivation in learning process and in cognitive skills. 
The learning process becomes much more enjoyable and the stress involved in the learning process is reduced [13].

Wang [14] has studied the effect of using communicative language games in teaching and learning English in Taiwanese primary and kindergarten schools. The aim of his study was to examine the use of communicative language games for teaching and learning English in Taiwanese schools. The results of the study provided encouraging evidence to indicate that Taiwanese school- teachers generally appreciated the benefits and value of communicative game activities in the teaching of English language. The findings also suggest that when facing students with different backgrounds, learning styles, needs, and expectations, teachers should be aware to take learners' individual variations into account and be more flexible in their use of communicative games in order to maximize educational effect. It is hoped that communicative language games will attract more attention and will be applied more widely in the classroom with more positive attitudes on the part of language teachers.

\section{Games, Communication and Creativity}

There is the general and popular hypothesis that computer game play has a negative effect on children in terms of their social life, creativity and communication with their friends. Creativity has been defined as a mental process involving the generation of new ideas or concepts, or new associations between existing ideas or concepts. From a scientific standpoint the products of creative thought are usually considered to have both originality and appropriateness. Although creativity appears to be a simple concept in the parlance of everyday life, its meaning and measurement have eluded the scientific community for decades [15].

This opinion exists because usually, children who play games stay at home with their tablet or computer and have less social interaction with their peers. However, some recent surveys reveal that the reality is not like that. Three surveys among school children showed that the frequency of video game use had no correlation with children's popularity among classmates. Additionally, another study found that children who played console games developed higher sociability than children who did not. Similarly, heavy video game players (usually students from elementary classes) were more likely to see their friends outside school and had a need to see their friends on a regular basis than non-players. Taking the above under consideration, the authors concluded that computer game play could be a positive feature of a healthy adolescent. One of the reasons that playing video games does not result in isolation but rather improve sociability might be that when adolescents play video games, they do not just play by themselves but with friends and family. They also exchange their gaming experiences with peers, not only face to face but also through the Internet [16].

There are many applications, which use music for learning, communication and creativity. My ABCs by BabyBus is a game that aims to learn colours to children with music. Furthermore, the ABC expands the limits of imagination and creativity as with the support of music and voice help kids learn the colours improving their memorizing skill. The game includes issues such as creative and attractive design, intuitive 
control design for children, ability to save a photo, touch and fill or paint with fingers and voice prompt invitation that allow children to learn in a friendly, creative and fun environment [17].

Additionally, the Kid Song Machine is an application that provides an enjoyable and fun game with new songs and the children feel relaxing with their interactions. The features of this application include fun songs to dance, sing and clap hand along with song lyrics shown for learning process, interactions with song effects and a lot of action. The developers believe that this game gives the opportunity to children to use their imagination and their creativity while the whole family may use it. Lastly, is a game that improves the children's learning process and their techniques about learning [10].

\section{$5 \quad$ Games and Cognitive Abilities}

Playing computer games demands that the users acquire certain cognitive skills, such as proactive and recursive thinking, systematic organization of information, interpretation of visual information, general search heuristics, means-ends analysis, and so forth [18]. It is, thus, hypothesized that playing computer games can help children develop cognitive skills. Considerable empirical evidence supports the claim that cognitive skills obtained in playing computer games can be transferable to other tasks.

Greenfield et al. [19] found that exposure to computer games either in the long term through the natural experience of playing games or in the short term via the use of games as part of experimental manipulation - was positively correlated with better cognitive skills in understanding and interpreting scientific and technical information presented graphically on the computer screen. Some evidence also suggests that computer games enhance inductive reasoning and facilitate the development of complex thinking skills related to problem solving, strategic planning and self-regulated learning. Computer games also enable the development of different learning styles, since the speed and the level of difficulty can be adjusted according to the player [20].

Furthermore, another study examined the ability of preschool children to manipulate basic concepts of probabilities using a game in the classroom. In this study, 50 preschoolers participated in a computer game, named "Shoes and Squares" and were tested on whether they can guess the most probable outcome in conditions of unequal likelihood of events. Participants were asked to make predictions and guess the most likely option in a random game composed by electronic items that represented cards with shoes and/or squares. The results of the study showed that children were personally engaged, they made estimations and seemed to get affected by the structural changes among the sample space. According to the developers, such findings raise educational implications concerning not only the teaching and constructing of probabilities in preschool education but also the role and use of technological games in the classroom As computer-based games allow the transition from hands-on experiences to abstract learning technological applications s should be integrated in the preschool classroom in order to enrich the educational procedure [21]. 


\section{Games and Maths}

Computer games constitute an important part of young children's lives within school contexts as games are often used to practice a particular mathematic skill or in order to motivate students to engage with conceptual material or ideas. As a result, there has been systematic study of the use of computer games in school while some teachers have incorporated them into the school programs in a more integrated way[22].

Taking this under consideration, a recent research investigated mathematical learning and understandings. The findings of this research showed that mathematical understandings can be promoted and practiced in computer games and that the structure and design of the game may determine the amount and quality of the interactions that children engage in. Children of all ages seem to prefer games that have a design element and cater for different levels of participation. Additionally, the data that was collected showed that children like games that have a narrative and adventure context in which activities show a purpose [23].

In addition, Siegler and Ramani [24] developed 'The Great Race' and demonstrated better number comparison, number naming and counting skills with playing number board games that required children to spin a spinner and then move one or two numbers on the board until they reached 10. Playing these games, during 2 weeks of 4 sessions of 20 min each, resulted in improvements.

A similar study was conducted by Baroody, Eiland, and Thompson [25] where kindergartners were instructed for 10 weeks, three times a week in small groups, using manipulatives and games focusing on basic number concepts, counting and numerical relations. All groups made significant gains in an early math assessment, but it lacked a non-intervention control group to determine if the gains were due to the intervention.

Although contradictory results have been found concerning the educational effectiveness of CAI games several studies revealed that CAI could be effective as an arithmetic support [26]. Wilson, Revkin, Cohen, Cohen, and Dehaene [27] developed the 'Number Race' for children aged 4-8 years old which is a game based on the idea that number skills develop from approximate representations of magnitudes. These representations are connected to numbers with the aid of counting and train children by presenting problems adapted to the performance level of the individual child. Children play games with all number formats, practice counting with numbers 1- 40 and do additions and sub- tractions in the range 1-10. The results of the study show that playing the computer game during 5 weeks children enhance number comparison skills in grade 1 of elementary school and improve their counting skills after the training.

\section{$7 \quad$ Games and Motor Skills}

Cognitive and psychomotor development of young children is based on physical manipulation and handling while many researchers have been promoting the pedagog- 
ical values of object manipulation since children can investigate the properties and behaviour of physical manipulatives. Nowadays, computers, laptops, interactive whiteboards and also tabletops have been introduced in school environments. Most computer educative games oriented to young children use multitouch based interfaces, to provide virtual representations that are as meaningful to children as physical objects, combining the motivation with the capabilities of digital technologies to adopt pedagogical content [28].

The tangible interaction approach has in recent years become a promising alternative to multitouch tabletops for very young children. Children learning with tangible user interfaces can benefit from the same pedagogical values as learning with materials in physical play. In a recent study, the design process of a tangible game for a tabletop device (NIKVision) was presented. NIKVision is scoping to give leisure and fun while reinforcing physical manipulation and co-located gaming for preschool children. By following an engineering design lifecycle, the designers developed a Farm Game for the tablet.Interaction is provided by the handling of conventional toys and computer augmentation on a table surface. According to the experience obtained by the developers the results crystalized in a set of reflections about the feasibility of designing with very young children and about the value of the data obtained from them. In fact, the initial results reinforce the idea of not trying to substitute but rather to assist teachers and emphasise the possibilities offered by the tabletop as a tool to promote student autonomy [29].

\section{Games and Special Education}

Pre-school children's learning disabilities include biological/genetic disorders, perceptual-motor disorders, and visual processing disorders. In other words, neuropsychological learning disabilities are related to pre-school skills groups that the child requires for learning. One of problems of pre-school children with neuropsychologi$\mathrm{cal} /$ developmental disabilities is executive functions and attention that involves abilities needed by children to learn school lessons. Observed characteristics in these children are delayed motor development, language delays, speech disorders, poor cognitive and conceptual development [30].

Video game therapy for children with ADHD has elicited a large amount of scholarly attention, because many children who do not inhibit their hyperactivity in other contexts will do so when playing intrinsically motivating video games. Lawrence et al. [31] highlighted that 6-12-year-old boys with ADHD perform beneath a normally developing control group when playing a cognitively demanding adventure video game, and even more so on a route task outside the laboratory, but perform equally well on a motor-skill targeting game that does not involve high working memory or distractor loads. This engagement makes video games ripe for therapeutic applications.

Moreover, during the last years there is considerable advance in the research on innovative computer technologies for the education of people with special needs such as patients with Autistic Spectrum Disorder. The specialists and educators are aided by 
interactive environments in facing the daily abnormal reactions by autistic children that can generally be classified as problematic social interaction, communication impairment dealing with verbal and non-verbal channels [32].

Various interactive environments have been developed for helping children with autism and in most of the cases these environments are software-educating platforms. In order to provide knowledge in an attractive way, these platforms use entertaining content in educational settings; photos of daily life or sketches are presented on the monitor of a computer so as to encourage people with autism to distinguish objects based on their size, color, type, etc. Moreover, these kinds of interactive learning platforms motivate the children to correlate the objects with sounds and words [33]. Additionally, robotic systems are often included in the interactive environments. Developed as interactive toys for children, humanoid robots are used as research platforms for studying how a human can teach a robot, using imitation, speech and gestures. Increasingly, robotic platforms are developed as interactive playmates for children. Recent literature reveals that robots generate a high degree of motivation and engagement in autistic persons, including those who are unlikely or unwilling to interact socially with human educators and therapists [34].

Furthermore, dyslexia is one of the main cognitive disabilities affecting the reading acquisition and thus is of crucial importance to obtain early diagnosis and help affected children as soon as possible. Generally, dyslexia is diagnosed not earlier than primary school as difficulties in reading is used as first indicator. Yet, being able to detect and treat this problem even in preschool years would ensure better chances to limit its impact and help the child's future reading ability. To this aim a research team designed a series of serious games to train specific skills that have been proven to be effective against dyslexia. Specifically in this study a system composed by various serious games designed for predicting the risk of developing dyslexia in very young children training also phonological skills and the visual-spatial attention, which are usually impaired in these children, in order to improve their future reading ability. The results of the study that were encouraging voiced that such serious games can be used as daily treatment with a low probability of drop out allowing a discrimination between children with a high risk of dyslexia and other children, based on the players' performance [35].

\section{Teachers' beliefs about serious games integration in the classroom}

The existing research on teachers' beliefs on ICT games is rather limited. As ICT is gaining ground in our everyday lives, we can hardly imagine an educational system without the presence of ICT. Most children use new technology before they even go to preschool. The appearance of ICT in the educational system is regarded as a necessity, as technology is put among the core subjects of learning in the school. However, Fullan [36] supports that the change on the educational field depends on what teachers do and think. Teachers have the responsibility for carrying new ideas and new procedures in the classroom and effectively integrating them in their teaching and learning 
method. Additionally, teachers are the ones that are engaging with other teachers' opinions about the adoption of a new policy or a new method, as they are less likely to engage with policy documents, but instead engage mostly with fellow teachers, and then with administrators and specialists.

According to Rosas et.al [37] the adoption of games through computer technology in the classroom still creates resistance. This resistance is based mainly on the teachers' perception that games is a difficult, demanding and not a useful instructional tool and their beliefs that there is not sufficient development of effective educational hardware and software. In the research done by Demirbilek and Tamer [38] math teachers' perspectives on using educational computer games in math education were examined. According to the findings, some of the teachers were arguing that computer games should not be fun-oriented, using games in math teaching is not appropriate in spite of the fact that some teachers arguing that the implementation of computer games would affect education positively.

Furthermore, even though the educational new technology games are a considerably new tool, it seems that teachers know the existence of them and they know where to find them, regardless whether they are using them or not. Furthermore, teachers agree with the fact that children do know how to use digital devices and they do play games using their parents' devices. However, articles and books on the use of educational digital games among young children in the early childhood education are rather limited. Since the use of digital devices and digital games by children is increasing, there is need for more empirical evidence and research on how they should be used and how teacher should adopt them [39].

\section{Conclusions}

Early childhood is commonly defined as the age where learning is of great importance as it contributes to the development of the child. Researchers claim [40] that preschool education aims at children acquiring and developing knowledge and values while learning is closely related to the development of the whole child. Thus, learning is related to cognitive, social, emotional, physical, and cultural development Therefore, the learning in early childhood has a broad character and is of a multidisciplinary nature [41].

The results of our brief review provide understandings about the ways in which young children collaborate whilst playing games, acquire better literature, cognitive, math, motor and communication skills with the support of serious games and new technology while children who face learning and developmental difficulties have the opportunity to develop better strategies to face their problems. Serious games seem to be incorporated into school program in a variety of ways and good quality of games seem to help children to explore different concepts with a variety of media.

Despite the fact that is evident the concerns about the use of serious games and new technology in preschool education, according to our review teachers should encourage collaborations on computer-based work and afford the opportunity for children in whole group times to share ideas and strategies, cooperate with parents and 
game developers in order to help the sensitive and important preschool age adopting new and innovative teaching methods with the support of serious games.

Last but not least, we would like to conclude with the view and the belief that serious games is an innovative teaching method that can enhance learning and entertainment in the preschool field improving and supporting children with different needs. We have also the consideration that the support and the views of teachers may change the role (in a better way) of the serious games in this field of kindergarten if companies and researchers give them the appropriate guidelines and help in the domains the need. Lastly, we hope that the sensitive and important field of preschool end special preschool education demands more investigation and more support of this kind of education scoping to cover main difficulties and needs that preschoolers face.

\section{References}

[1] Bos, N. D., Shami, N. S., \& Naab, S. (2006). A globalization simulation to teach corporate social responsibility: Design features and analysis of student reasoning. Simulation \& Gaming, 37(1), 56-72 https://doi.org/10.1177/1046878106286187

[2] Cumberbatch, A. R. (2000). The effect of outdoor environmental education on in-class behaviors of sixth, seventh and eighth grade students

[3] Susi, T., Johannesson, M., \& Backlund, P. (2007). Serious games: An overview.

[4] Parlett, D. S. (1999). The Oxford history of board games. Oxford University Press, USA

[5] Persson, N. (2014). Serious Games: Present and Future

[6] Gros, B. (2007). Digital games in education: The design of games-based learning environments. Journal of Research on Technology in Education, 40(1), 23-38 https://doi.org/10.1080/15391523.2007.10782494

[7] Kirriemuir, J. (2002). Video Games and Gaming Consoles. The relevance of video games and gaming consoles to the Higher and Further Education learning experience. Available: http://www.jisc.ac.uk/index.cfm?name=techwatch report 0201

[8] Segers, E. \& Verhoeven, L. (2003). Effects of vocabulary training by computer in kindergarten. Journal of Computer Assisted Learning, 19, 557-566 https://doi.org/10.1046/j.02 66-4909.2003.00058.x

[9] Schuurs, U. (2012). Serious gaming and vocabulary growth. In Serious Games: The Challenge (pp. 40-46). Springer Berlin Heidelberg https://doi.org/10.1007/978-3-642-33814$\underline{45}$

[10] Kitichaiwat, P., Thongsuk, M., \& Ngamsuriyaroj, S. (2014, March). Melody Touch: A game for learning English from songs. In Student Project Conference (ICT-ISPC), 2014 Third ICT International (pp. 13-16). IEEE https://doi.org/10.1109/ICTISPC.2014.6923207

[11] Annetta, L. A., Murray, M., Gull-Laird, S., Bohr, S., \& Park, J. C. (2006). Serious games: In- corporating video games in the classroom. Ed- ucause Quarterly, 29(3), 16-22. Retrieved Octo- ber 2, 2006, from http://www.educause.edu/apps/ eq/eqm06/eqm0633.asp

[12] Turgut, Y., \& Irgin, P. (2009). Young learners' language learning via computer games. Procedia-Social and Behavioral [14] Sciences, 1(1), 760-764 https://doi.org/10.1016/ j.sbspro.2009.01.135

[13] Aghlara, L., \& Tamjid, N. H. (2011). The effect of digital games on Iranian children's vocabulary retention in foreign language acquisition. Procedia-Social and Behavioral Sciences, 29, 552-560 https://doi.org/10.1016/j.sbspro.2011.11.275 
[14] Wang, Y.H. (2010). Using communicative language games in teaching and learning English in Taiwanese primary schools. Journal of Engineering Technology and Education, 7(1), 126-142

[15] Runcho, M. A., \& Albert, R. S. (2010). Creativity research. In J. C. Kaufman \& R. J. Sternberg (Eds.), The Cambridge handbook of creativity. NY: Cambridge University Press. https://doi.org/10.1017/CBO9780511763205.003

[16] Lee, K. M., \& Peng, W. (2006). What do we know about social and psychological effects of computer games? A comprehensive review of the current literature. Playing video games: Motives, responses, and consequences, 327-345.

[17] Itamar, E., \& Itai, A. (2008, May). Using Movie Subtitles for Creating a Large-Scale Bilingual Corpora. In LREC.

[18] Pillay, H. (2003). An investigation of cognitive processes engaged in by recreational computer game players: Implications for skills of the future. Journal of Research on Technology in Education, 34, 336-349 https://doi.org/10.1080/15391523.2002.10782354

[19] Greenfield, P. M., Brannon, G., \& Lohr, D. (1994). Two-dimensional representation of movement through three-dimensional space: The role of video game expertise. Journal of Applied Developmental Psychology, 1, 87-103 https://doi.org/10.1016/01933973(94)90007-8

[20] Jenkins, H. (2002). Game theory. Technology Review, 29, 1-3

[21] Nikiforidou, Z., \& Pange, J. (2010). "Shoes and Squares": A computer-based probabilistic game for preschoolers. Procedia-Social and Behavioral Sciences, 2(2), 3150-3154. https://doi.org/10.1016/j.sbspro.2010.03.480

[22] Yelland, N.J. (1998) Making Sense of Mathematics, Gender and Technology, in N.J. Yelland (Ed.) Gender in Early Childhood. London: Routledge.

[23] Yelland, N. J. (2002). Playing with ideas and games in early mathematics. Contemporary issues in early childhood, 3(2), 197-215 https://doi.org/10.2304/ciec.2002.3.2.4

[24] Siegler, R. S., \& Ramani, G. B. (2009). Playing linear number board games e but not circular ones e improves low-income preschoolers' numerical understanding. Journal of Educational Psychology, 101(3), 545e560

[25] Baroody, A. J., Eiland, M., \& Thompson, B. (2009). Fostering at-risk preschoolers' number sense. Early Education and Development, 20(1), 80e128. https://doi.org/10.1080/104 09280802206619

[26] Butterworth, B., \& Laurillard, D. (2010). Low numeracy and dyscalculia: identifica- tion and intervention. ZDM The International Journal on Mathematics Education, 42(6), 527539 https://doi.org/10.1007/s11858-010-0267-4

[27] Wilson, A. J., Revkin, S. K., Cohen, D., Cohen, L., \& Dehaene, S. (2006). An open trial assessment of "The Number Race", an adaptive computer game for remediation of dyscalculia. Behavioral and Brain Functions, 2, 20 https://doi.org/10.1186/1744-9081-2-20

[28] Magerkurth, C., Cheok, A.D. and Nilsen, T. (2005). Pervasive Games: Bringing Computer Entertainment Back to the Real World. ACM Transactions on Computers in Entertainment, Vol. 3, No. 3. Article 4a. https://doi.org/10.1145/1077246.1077257

[29] Marco, J., Baldassarri, S., \& Cerezo, E. (2013). NIKVision: Developing a Tangible Application for and with Children. J. UCS, 19(15), 2266-2291.

[30] Abedi A, Malekpour M, Moulavi H, et al. Neuro- psychological aspect of preschool with and without neuropsychological developmental learning disability. Research on exceptional children2008;8(1): 1-18.[In Persian]

[31] Lawrence, V., Houghton, S., Tannock, R., Douglas, G., Durkin, K. \& Whiting, K. (2002) ADHD outside the laboratory: Boys' executive function performance on tasks in video- 
game play and on a visit to the zoo. Journal of Abnormal Child Psychology, 30, 447-462 https://doi.org/10.1023/A:1019812829706

[32] Luneski, A., Konstantinidis, E. I., Hitoglou-Antoniadou, M., Bamidis, P. D. (2008). Affective Computer-Aided Learning for Autistic Children, Workshop of Child, Computer and Interaction (WOCCI '08) Chania, Greece

[33] Lányi, C. S., Tilinger A. (2004). Multimedia and Virtual Reality in the Rehabilitation of Autistic Children, Computers Helping People with Special Needs, 3118/2004, p. 625

[34] Robins, B., Dautenhahn, K., Boekhorst, R. T., Billard, A. (2005). Robotic assistants in therapy and education of children with autism: can a small humanoid robot help encourage social interaction skills? Published online: 8 July 2005, Springer-Verlag

[35] Gaggi, O., Galiazzo, G., Palazzi, C., Facoetti, A., \& Franceschini, S. (2012, July) A serious game for predicting the risk of developmental dyslexia in pre-readers children. In Computer Communications and Networks (ICCCN), $201221^{\text {st }}$ International Conference on (pp. 15). IEEE https://doi.org/10.1109/ICCCN.2012.6289249

[36] Fullan, M. (2007). The new meaning of educational change. $4^{\text {th }}$ edition. New York : Teachers College Press ; London : Routledge

[37] Rosas, R., Nussbaum, M., Cumsille, P., Marianov, V., Correa, M., Flores, P., Grau, V., Lagos, F., Lopez, X., Lopez, V., Rodriguez, P., Salinas, M. (2011). Beyond Nintendo: design and assessment of educational video games for first and second grade students. Computers \& Education, v. 40, p. 71-9 https://doi.org/10.1016/S0360-1315(02)00099-4

[38] Demirbilek, M., Tamer, S.L. (2010). Math teachers' perspectives on using educational computer games in math education. Procedia Social and Behavioral Sciences, vol. 9, p. 709-716. https://doi.org/10.1016/j.sbspro.2010.12.222

[39] Raptopoulou, A. T. (2015). Mind the Gap: A qualitative study on preschool teachers' perception on digital game-based learning.

[40] Hjalmarsson, M., \& Löfdahl, A. (2014). Being caring and disciplinary-male primary school teachers on expectations from others. Gender and Education, 26(3), 280-292 https://doi.org/10.1080/09540253.2014.901731

[41] Rosen, D., Wang, X. C., \& Yelland, N. (2008). Framing the Research on Technology and Student Learning in Early Childhood Education. Framing Research on Technology and Student Learning in the Content Areas, 101-118.

\section{Authors}

Georgia Kokkalia (MSc in Specific Learning Difficulties) is a Special Education Teaching Professional and Phd Candidate in University of Athens. She has participated in various research projects regarding the use of Information and Communication Technologies (ICTs) in Special Education and in Kindergarten (E- mail: gioulina@hotmail.com).

Athanasios Drigas is a director of research at N.C.S.R. Demokritos. He is the Coordinator of Telecoms Lab and founder of Net Media Lab since 1996. From 1985 to 1999 he was the Operational manager of the Greek Academic network. He has been the Coordinator of Several International Projects, in the fields of ICTs, and e-services (e-learning, e-psychology, e-government, e-inclusion, e-culture etc). He has published more than 200 articles, 7 books, 25 educational CD-ROMs and several patents. He has been a member of several International committees for the design and coordina- 
tion of Network and ICT activities and of international conferences and journals (Email: dr@iit.demokritos.gr).

Alexandra Economou is an associate professor at the University of Athens in the department of Psychology. She teaches undergraduate and postgraduate neuropsychology and experimental psychology courses at the University of Athens in the Department of Psychology while her interests focus on cognitive and biological psychology. Dr. Economou is also vice-president of the Greek Aphasia Association (E-mail: aoikono@psych.uoa.gr).

Petros Roussos is an assistant professor at the University of Athens in the department of Psychology. Since 1994 he has taught cognitive psychology, research methods and statistics in psychology at the University of Crete (Greece), the University of the Aegean (Greece), the University of Athens and many other colleges and higher education institutions. He has served as adjunct research fellow of the Hellenic Pedagogical Institute (1998-2000), as Psychology Department Chair at the University of Indianapolis Athens Campus (2000-2004) and as Researcher at the Unit of Analysis and Documentation at the Greek Ministry of Employment and Social Protection (2004-2005). He is also a graduate member of the British Psychological Society, member of the Hellenic Psychological Society, and General Secretary of the Hellenic Cognitive Science Society (E-mail: roussosp@psych.uoa.gr).

Spyridoula Choli is a Speech and Language Therapist while she has completed her $\mathrm{PhD}$ in "Aphasia in people with brain lesions", with a scholarship at National and Kapodistrian University of Athens. Her first MSc in "Speech and Language TherapyCounselling", was completed at National and Kapodistrian University of Athens on June 2005 and her second MSc in "Speech and Language Therapy" was completed at City University in London. She currently works as a Speech and Language Therapist and as a Special Teacher in Special Schools. Throughout the years she has acquired big experience in paediatrics, as she has been working in various contexts with preschool and school children (E-mail: linaholi@yahoo.gr). 